\title{
A Method for Specific Amplification and PCR Sequencing of Individual Members of Multigene Families: Application to the Study of Steroid 21 - Hydroxylase Deficiency
}

\author{
Simon Collier, Mayada Tassabehji, and Tom Strachan \\ University Department of Medical Genetics, St. Mary's Hospital, \\ Manchester, M13 OJH, UK
}

Mutations at the human HLA-linked CYP21B locus are responsible for 21-hydroxylase deficiency, a recessively inherited disorder of steroidogenesis. The scope for PCRbased analysis of the CYP21B gene has been restricted by the very high sequence homology between CYP2IB and a closely related pseudogene, CYP21A. Here we describe a novel PCR sequencing strategy that allows the independent amplification of the entire CYP21B coding sequence and the subsequent enzyme-mediated conversion of the PCR product to a single-stranded form for dideoxy sequencing. We have used this approach to characterize the 21-hydroxylase deficiency allele associated with HLA-B55, the most frequent HLA marker associated with a CYP21B point mutation in the British population, and also an HLA-B35 associated allele of Asian origin. Allele-specific oligonucleotide (ASO) hybridization analyses have confirmed the selective amplification of CrP21B genes and the identity of the pathological mutations. The method can be adapted to permit selective amplification and PCR sequencing of individual closely related members of other multigene families and smallcopy-number repetitive DNA families.
$S$ ective in vitro amplification of individual members of a repetitive DNA family is often desirable for identifying locus-specific characteristics of interest such as map position, DNA structure, and gene expression in multigene families. In the case of high sequence homology between nonallelic members of a repetitive DNA family, primers that have been selected to amplify a specific locus may also bind to other members of the family. Ensuing amplification products will therefore constitute a mixture of nonallelic sequences and also artificial heteroduplexes formed between complementary strands of nonallelic sequences.

The above problem is particularly relevant to the human steroid 21hydroxylase and complement $\mathrm{C} 4$ gene families. Each of these families is defined by highly related genes that are clustered in the HLA complex on the short arm of chromosome 6 , and are flanked by highly polymorphic HLA genes both centromerically (e.g., HLA-DR genes) and telomerically (HLA-B, HLA-C, and HLA-A). Normally, the 21-hydroxylase/complement $\mathrm{C} 4$ gene cluster on chromosome 6 consists of two tandemly repeated units, each about $30 \mathrm{~kb}$ long and containing a 21hydroxylase gene and a C4 gene ${ }^{(1,2)}$ (see Fig. 1A). One unit contains a normally functional 21-hydroxylase gene, $C Y P 21 B$, and a complement $C 4$ gene, $C 4 B$. The neighboring unit con- tains a 21-hydroxylase pseudogene, CYP21A, whose nucleotide sequence shows about $97 \%$ identity to that of the $C Y P 21 B$ gene, ${ }^{(3-5)}$ and the complement $C 4 A$ gene which shows a similarly high degree of sequence identity to the $C 4 B$ gene.

The number of tandem 21hydroxylase/C4 gene units in a single cluster can vary from 1 to $4^{(6,7)}$ and sequence exchange between loci is known to occur by unequal crossover $^{(8)}$ and may also occur by gene conversion-like events (for recent reviews, see refs. 9 and 10). Indeed, all recorded pathological mutations at the CYP21B locus are thought to have occurred by these mechanisms. In approximately $25 \%$ of cases, pathological mutation results from loss of all or part of the CYP21B gene sequence following deletion due to unequal crossover. Such pathological deletion haplotypes are often associated with specific HLA antigens such as HLA-Bw47 and HLA$B 40(60)$. The remaining $75 \%$ of cases show pathological point mutations that are associated with a diverse set of HLA antigens. In each case that has been investigated so far, the mutation seems to have been copied from DNA sequence normally present in the CYP21A pseudogene, presumably by a gene conversion-like mechanism. Additional evidence for the role of gene conversion at this locus has been supplied by restriction fragment length 
variant (RFLV) (see ref. 6) analysis, allele-specific oligonucleotide (ASO) hybridization, and PCR-based studies. $(9,10)$

The variation in copy number and the sequence exchange between the 21-hydroxylase genes does not facilitate their analysis. In this paper we describe a PCR-based strategy that permits selective amplification of the entire $C Y P 21 B$ gene and its enzymatic conversion to a single-stranded form suitable for DNA sequencing.

\section{MATERIALS AND METHODS PCR Amplification}

Genomic DNA was initially digested to completion with a fivefold excess of TaqI (Boehringer-Mannheim). In the initial PCR reaction $0.5 \mu \mathrm{g}$ of Taqlrestricted DNA was amplified in a 100 $\mu \mathrm{l}$ reaction containing $6.7 \mathrm{mM} \mathrm{MgCl}_{2}$, $16.6 \mathrm{~mm}\left(\mathrm{NH}_{4}\right)_{2} \mathrm{SO}_{4}, 67 \mathrm{~mm}$ Tris- $\mathrm{HCl}$ (pH 8.4), $0.017 \%$ bovine serum albumin, 5\% dimethylsulfoxide, 2 units of Taq polymerase (Boehringer-Mannheim), and 50 pmoles of each of the oligonucleotide primers: $5^{\prime}$-CGACAGCTAGATTTCCGGCTGGAATC-3' , $5^{\prime}$ CGAGTTCTCGGTGCCCTTCACGGAA AT-3'. Amplification involved 30 cycles of DNA denaturation (45 sec at $\left.93^{\circ} \mathrm{C}\right)$, primer annealing $(1 \mathrm{~min}$ at $\left.65^{\circ} \mathrm{C}\right)$, and DNA synthesis $(3 \mathrm{~min}$ at $72^{\circ} \mathrm{C}$ ). The product of the initial PCR reaction was diluted 100 -fold with distilled water and $1-5 \quad \mu \mathrm{l} \quad(1 /$ $10000-1 / 2000$ of the total product) used as a template for secondary PCR amplification with the internal primers 5 '-CCCGTGATGCATATAGAGCATGGCTGTG- $3^{\prime}$ and $5^{\prime}$-CACGGAAATGAAGCTGAGACC- $3^{\prime}$. The reaction conditions were as above except that only 25 cycles were performed.

\section{Preparation and Dideoxy}

\section{Sequencing of Single-stranded DNA}

The product of the secondary PCR reaction was purified by selective binding to and elution from a solid matrix (Biorad, Prep-a-gene), and was digested to completion with a fivefold excess of Nsil in a buffer specified by the manufacturers (New England Biolabs). The reaction mixture was diluted by the addition of an equal volume of 10 $\mathrm{mM} \mathrm{MgCl}_{2}, 10 \mathrm{~mm}$ Tris ${ }^{\bullet} \mathrm{HCl}(\mathrm{pH} 8.0)$ and incubated for $1 \mathrm{hr}$ at $37^{\circ} \mathrm{C}$ with exonuclease III (100 units/ug). The

A

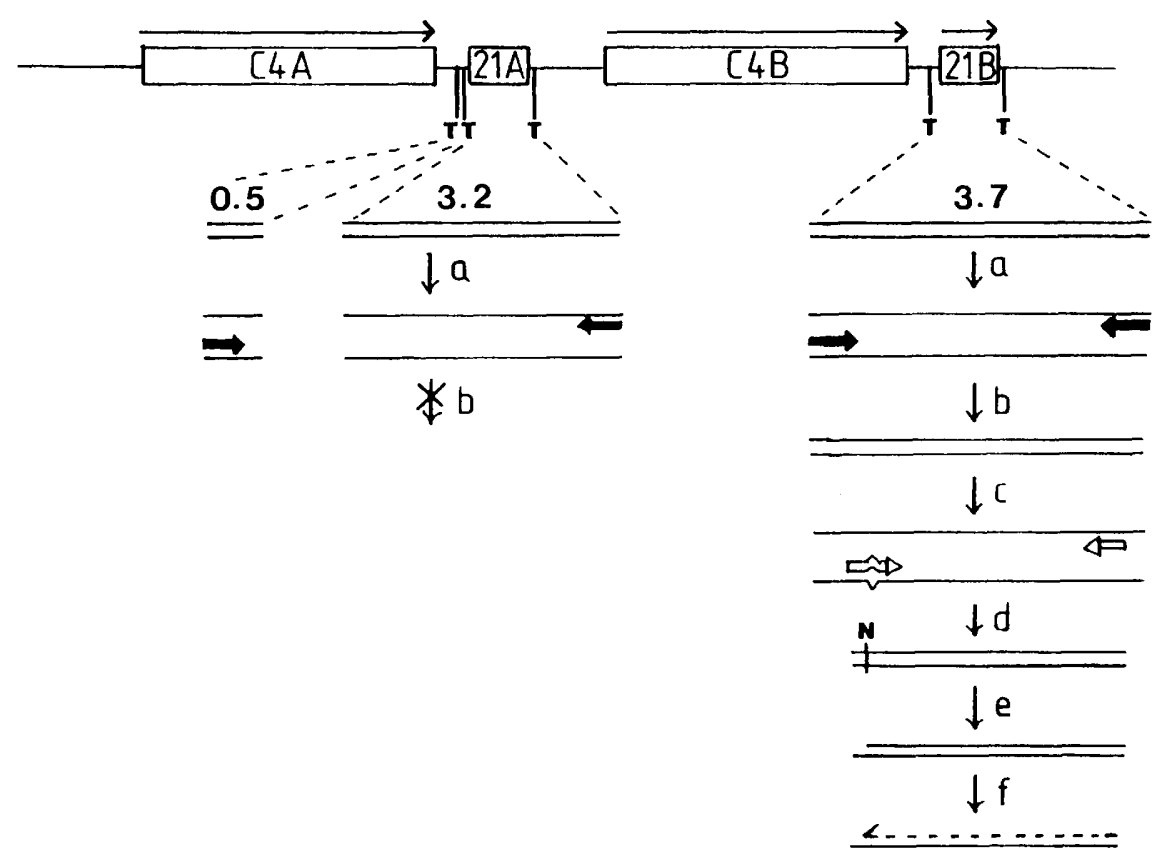

FIGURE 1 PCR sequencing strategy. (A) CYP21 and C4 gene organization. Arrows mark the direction of transcription of expressed genes. The direction from left to right is from telomere to centromere. (T) Relevant Tagl sites flanking the CYP21 genes. (B) Selective amplification of CYP21B genes and enzymatic production of single-stranded DNA templates for DNA sequencing. Numbers refer to the size in kilobases of $T a q I$ restriction fragments deriving from the CYP21A and CYP21B genes. Steps are: $a$ and $b$ ) Selective amplification of CYP21B genes using primers derived from the region immediately adjacent to the flanking Taql sites; ( $c$ and d) secondary PCR amplification using primers, one of which is deliberately mismatched to introduce a NsiI site $(\mathrm{N})$; $(e)$ digestion with NsiI; $(f)$ digestion with exonuclease III.

resulting single-stranded DNA was purified by phenolic extraction and ethanol precipitation and used as a template for dideoxy DNA sequencing (USB, Sequenase-2.0) using 16- and 17nucleotide-long oligonucleotide primers complementary to conserved regions of the CYP21B gene antisense strand.

\section{Allele-specific Oligonucleotide Hybridization to PCR Products}

Approximately $100 \mathrm{ng}$ of product from the initial PCR reaction was denatured by the addition of $\mathrm{NaOH}$ to a final concentration of $0.5 \mathrm{M}$ and slot-blotted in duplicate onto a nylon membrane (Amersham, Hybond $\mathrm{N}+$ ). The membrane was incubated in a $5 x$ SSPE, $5 x$ Denhart's prehybridization mix $(0.9 \mathrm{M}$ $\mathrm{NaCl}, 50 \mathrm{~mm} \mathrm{NaH} \mathrm{PO}_{4}, 20 \mathrm{~mm}$ EDTA, $0.1 \%$ Ficoll, $0.1 \%$ polyvinylpyrrolidone, $0.1 \% \mathrm{BSA}, \mathrm{pH} 7.4$ ) for at least 2 $\mathrm{hr}$ at $50^{\circ} \mathrm{C}$. Hybridization was subsequently carried out at $50^{\circ} \mathrm{C}$ overnight in the same solution containing $10 \mathrm{ng}$ of oligonucleotide probe that had been end-labeled using T4 polynucleotide kinase and $\left[\gamma^{32} \mathrm{P}\right] \mathrm{ATP}$. After hybridization, filters were washed with $5 \times$ SSPE $\left(0.9 \mathrm{M} \mathrm{NaCl}, 50 \mathrm{~mm} \mathrm{NaH} \mathrm{PO}_{4}\right.$, $20 \mathrm{~mm}$ EDTA, pH 7.4) at room temperature and then with a tetramethylammonium chloride (TMA) wash solution (3 M TMA, $50 \mathrm{~mm}$ Tris- $\mathrm{HCl} \mathrm{pH} 8,2 \mathrm{~mm}$ EDTA) initially at room temperature and subsequently at $55-58^{\circ} \mathrm{C}$. ${ }^{(11)}$ Allele-specific oligonucleotides were as follows: $173 \mathrm{~N} 5^{\prime}$-AGGTAACAGATGATGCTGC-3' ; 173M 5'-GCAGCATCAACTGTTACCT-3'; 319M 5'-CAGCGACTGCAGGAGGAGC-3 ${ }^{\prime} ; 319 \mathrm{M} \quad 5^{\prime}-$ GCTCCTCCTACAG-TCGCTG-3.

\section{RESULTS}

The basis of the PCR sequencing method is outlined in Figure 1. Selective amplification of the CYP21B gene was achieved using as a template for PCR amplification, genomic DNA that had been digested to completion with Taql. The primers used derive from sequences located in the immediate vicinity of well-conserved Taql restriction sites that flank both the individual CYP21A and CYP21B genes at positions approximately $3.7 \mathrm{~kb}$ apart. CYP21A genes can be distinguished 
TABLE 1. Nucleotide Alterations in Mutant CYP21B alleles



${ }^{\text {a }}$ Corresponding codon position in the majority of CYP21B genes; the mutant allele coincidentally has an additional codon because of a neutral length polymorphism in exon 1 .

from CYP21B genes because they have an additional TaqI site located between the conserved TaqI sites. Consequently, digestion of genomic DNA with Taql results in differential cutting: CYP21B genes are included in $3.7-\mathrm{kb}$ Taql fragments, and CYP21A genes are included in $3.2-\mathrm{kb}$ Taql fragments. Subsequent PCR amplification with the indicated primers will result in amplification of the CYP21B-specific 3.7-kb fragment. However, amplification of CYP21A genes does not occur because the PCR primers hybridize to sequence elements on different molecules; one primer hybridizes to a $0.5-\mathrm{kb}$ Taql fragment while the other hybridizes to the $3.2-\mathrm{kb}$ Taql fragment (see Fig. 1B, steps a and b).

Following selective amplification of CYP21B genes, the initial PCR product is used as a pool for secondary PCR amplification using nested primers, one of which is deliberately mismatched in order to introduce a NsiI site at one end of the PCR product. Nsil digestion of this product therefore results in a product with one blunt end and one overhanging 3 ' end (Fig. 1B, step e). As sufficiently long 3 ' singlestranded overhangs are not cleaved by exonuclease III,(12) the antisense strand, which has the overhanging $3^{\prime}$ end, will be resistant to exonuclease III digestion, whereas the sense strand will be susceptible to exonuclease III digestion. Following exonuclease IIl digestion, the resulting single-stranded antisense strand product can be used with sense strand-specific primers to permit DNA sequencing.

We have applied the above method to amplify and sequence the CYP21B genes in two 21-hydroxylase deficiency patients. One of the patients has the simple virilizing form of the disease in which homozygous deficiency in 21hydroxylase activity leads to the accumulation of steroid precursors proximal to the enzyme block and excessive steroid androgen biosynthesis (for review, see ref. 13). This patient has an HLA-Bw47-bearing haplotype that carries a $C Y P 21 B$ gene deletion, and a DR4 C4B6 C4A4 B55 A11 haplotype. The latter haplotype bears a mutant CYP21B gene and is the most common extended haplotype of this kind in the U.K. population. ${ }^{(6)}$ DNA sequencing of the $3.7-\mathrm{kb}$ PCR product from this patient shows a CYP21B sequence with a few nucleotide changes (see Table 1). They include a $\mathrm{T} \rightarrow \mathrm{A}$ missense mutation at codon 173 that results in an isoleucine to asparagine amino acid change (Fig. 2, left panel). This change, which is alternatively found at codon position 172 of some CYP21B alleles due to length polymorphism in exon 1 , has been previously shown to be pathological. ${ }^{(14-16)}$ The mutation results in sequence identity in the region of the pathological mutation between the mutant gene and the corresponding CYP21A sequence, suggesting a gene conversion-like origin.

A second possible gene conversion event has introduced a $\mathrm{T}$ residue at a position four nucleotides upstream from the initiation codon. However, because we previously have observed this nucleotide change in an unaffected $C Y P 21 B$ deletion heterozygote (S. Collier, unpubl.), it seems likely to represent a neutral polymorphism at the CYP21B locus. The other two changes are missense mutations that 
do not appear to have originated by gene conversion. Of these, the change observed in the second last codon (494) has previously been reported in one functional CYP21B gene as well as two mutant alleles, ${ }^{(5,15)}$ suggesting that it does not contribute to pathogenesis. Additionally, although not previously reported, the change in codon 454 is unlikely to be pathogenic as we have previously observed this change in the single CYP21B gene of a deletion heterozygote who is clinically asymptomatic (S. Collier, unpubl.).

The second 21-hydroxylase deficiency patient has the "salt-wasting" form of the disease; in addition. to excessive androgen biosynthesis, there is an inability to conserve dietary sodium as a result of a deficiency in aldosterone biosynthesis. ${ }^{(13)}$ This patient is HLA-homozygous as a consequence of known parental consanguinity and has a single type of $C Y P 21 B$ gene located on an HLA-DR2 B35 A3 haplotype. DNA sequencing analysis of the PCR product from this patient has also revealed a $C Y P 21 B$ gene sequence that diverges from the sequence of normal
CYP21B genes at a very small number of nucleotide positions (see Table 1). One of the changes is a $C \rightarrow T$ transition which results in a nonsense mutation at codon 318 (Fig. 2, middle panel). This mutation has previously been defined as pathological(17) and appears to be the result of gene conversion from the pseudogene. Other mutational differences include an $A \rightarrow G$ transition in the second last codon which, as described above, is not thought to be pathogenic. In addition, there is a $\mathrm{C} \rightarrow \mathrm{A}$ transversion in the second intron at a nucleotide position which is the location of a splice site mutation in some mutant $C Y P 21 B$ alleles. ${ }^{(4,5)}$ The same nucleotide change, however, has been reported not to alter normal splicing of the CYP21B gene, ${ }^{(4)}$ suggesting that it is does not contribute to disease.

As a check on the ability of the method to amplify CYP21B genes selectively, and as confirmation of the sequence data, we have probed the primary PCR product from both patients using a panel of allele-specific oligonucleotides. These comprised pairs of $C Y P 21 B$-specific and $C Y P 21 B$ mutant specific (CYP21A-specific) oligonucleotides for the two candidate sites of pathological mutation. As expected, the primary PCR product from the deletion heterozygote patient showed no evidence of hybridization with a CYP21B-specific ASO encompassing codon 173 , but strong hybridization with the mutant-specific ASO for this region (Fig. 2, right panel). However, the same DNA showed positive hybridization with a CYP21B-specific ASO encompassing codon 318 , but no hybridization with the equivalent $C Y P 21 B$ mutant-specific (= CYP21A-specific) ASO. Reciprocal results were obtained with the primary PCR product from the second patient. The lack of ambiguity in these results confirms the ability of the method to amplify $C Y P 21 B$ genes selectively.

\section{DISCUSSION}

Steroid 21-hydroxylase deficiency is the most outstanding example of disease due to intragenomic sequence exchanges; all pathological mutations

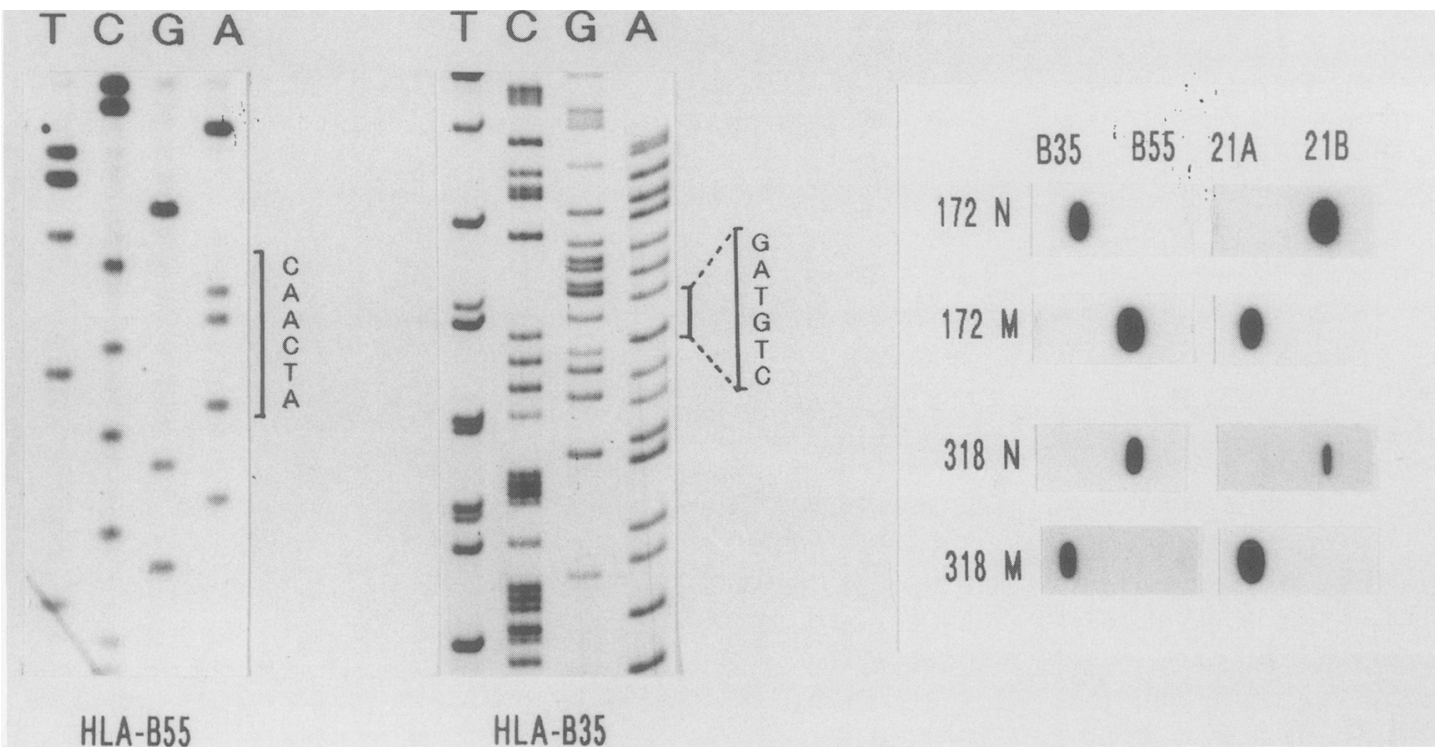

FIGURE 2 PCR sequencing and ASO hybridization analysis at sites of pathological mutation in mutant CYP21B genes. (Left) DNA sequence spanning a missense mutation in the mutant CYP21B gene of an HLA-B55 deletion heterozygote patient. The interpreted hexanucleotide sequence corresponds to codons 172 and 173 in this gene. (Middle) DNA sequence spanning a nonsense mutation in the mutant $C Y P 21 B$ gene of an HLA-B35 homozygous patient. The interpreted hexanucleotide sequence corresponds to codons 317 and 318 . (Right) ASO hybridization. DNA sources as follows: B35, amplified CYP21B genes from an HLA-B35 homozygous patient; B55, amplified CYP21B gene from an HLA-B55 deletion heterozygote patient; $21 \mathrm{~A}$, control CYP21A gene DNA; 21B, control CYP21B gene DNA. ASOs were as follows: $172 \mathrm{~N}$ and $172 \mathrm{M}$, ASOs specific for a sequence encompassing codon $172(173)$ in the normal CYP21B gene (N), or in the corresponding mutant (M) sequence; $318 \mathrm{~N}$ and $318 \mathrm{M}$, ASos specific for a sequence encompassing codon $318(319)$ in the normal CYP21B gene (N), or in the corresponding mutant (M) sequence. 
that have been recorded at the CYP21B locus appear to be due to gene conversion-like mechanisms (this paper and previous reports; for recent reviews, see refs. 9 and 10), or to gene deletion arising as a result of unequal crossover and probably also unequal sister chromatid exchanges. ${ }^{(8-10)}$ Because all pathological point mutations at the CYP21B gene appear to arise by copying sequence from the CYP21A pseudogene, PCR-based assays of pathological mutation at the CYP21B locus have been restricted in scope because of coamplification of CYP21A sequences.

To overcome this, PCR assays have recently been devised by taking advantage of intragenic locations where the CYP21A and CYP21B gene sequences are suitably divergent. $(19,20)$ However, the use of intragenic primers to amplify CYP21B-specific sequence selectively is disadvantaged by the following: (1) the interpretation of the results is not facilitated by ignorance of the sequence corresponding to the primer binding sites of the CYP21A and $C Y P 21 B$ genes under study; (2) the PCR products are gene fragments so that assay pf mutations (by ASO probing or DNA sequencing) at different ends of the $C Y P 21 B$ gene may require interpretation of different PCR products which cannot be shown to have derived from the same gene. For example, chance occurrence by gene conversion of a $C Y P 21 B$-specific primer binding site in a $C Y P 21 A$ gene may result in co-amplification of unwanted CYP21A gene sequence.

The method of PCR sequencing described in the present report overcomes these limitations. First, the PCR product encompasses the entire CYP21B gene. Additionally, the choice of primers from sequence adjacent to the flanking TaqI sites ensures immediate correlation with genomic TaqI Southern hybridization results. This is advantageous because genomic TaqI Southerns are almost universally used as an initial step in investigating the possibility of CYP21B gene deletion. Finally, the method described herein has the advantage that it permits rapid PCR sequencing of CYP $21 B$ genes; a full-length genic PCR product is converted enzymically to a single-stranded form suitable for DNA sequencing using $C Y P 21 B$-specific primers. Al- though much attention has recently been paid to the extreme sensitivity of the PCR reaction, the potential for contamination of the primary $3.7-\mathrm{kb}$ amplification product by CYP21A sequence does not appear to be a problem, as shown by the unambiguous demonstration of CYP21B-specific sequences by sequencing and ASO hybridization of the PCR products (see Fig. 2).

The above method can be modified to permit selective amplification of CYP21A genes. CYP21B genes, but not CYP21A genes, normally possess an internal KpnI site. A preamplification step with Kpnl, instead of TaqI, leads to selective cleavage of $C Y P 21 B$ genes and subsequent selective amplification of CYP21A genes (Collier et al., in prep.). The method can also be generally adapted to permit selective amplification and PCR sequencing in multigene families and other DNA sequence families in which there are a few individual members that are closely related in sequence. Unlike the ARMS amplification method which can discriminate between closely related sequences, ${ }^{(21)}$ the method described in this paper does not require DNA sequence information to identify locusspecific differences; instead, knowledge of specific restriction site differences is sufficient. Additionally, because the method does not require the use of locus-specific primers, the primers can be designed from highly conserved regions to amplify full-length genes as in the present paper.

To adapt the method of locusspecific amplification to any small family of highly homologous DNA sequences, two conditions are ideally required. First, some DNA sequence should be known concerning the locus of interest to permit the synthesis of primers spanning the desired region. Second, the region to be amplified in the locus of interest should consistently lack one or more restriction sites that are known to occur in the equivalent region in other members of the family. Digestion with the relevant restriction enzyme or enzymes should then cleave within the region of interest in all members of the family except the desired locus.

The method for enzyme-mediated production of single-stranded PCR pro- ducts can also be adapted to other loci. In the specific case of the CYP21B gene, we took advantage of a naturally occurring sequence that showed $5 / 6$ matches with the Nsil recognition sequence; the choice of a primer with an appropriate single mismatch then permitted the introduction of a Nsil site during secondary amplification. To generalize the method, a single amplification step can be used. One primer can be designed to contain an additional sequence at its 5 'end that encompasses a recognition site for an enzyme that produces a suitably overhanging 3 ' end (e.g., Apal, BanII, KpnI, Nsil, PstI, Sacl, or Sphl). The choice of which restriction site to include in the primer is determined by restriction mapping; only recognition sites for enzymes that do not cut in the region between the primer binding sites can be used. Following amplification, digestion with the appropriate enzyme can then generate a PCR product with a single overhanging $3^{\prime}$ terminus which will be resistant to exonuclease III digestion.

\section{ACKNOWLEDGMENTS}

We are grateful to the Wellcome Trust for financial support of this work.

\section{REFERENCES}

1. Carroll, M.C., R.D. Campbell, and R.R. Porter. 1985. Mapping of steroid 21-hydroxylase genes adjacent to the complement $\mathrm{C} 4$ genes in HLA, the major histocompatibility complex in man. Proc. Natl. Acad. Sci. 82: 521-525.

2. White, P.C., D. Grossberger, B.J. Onufer, D.D. Chaplin, M.I. New, B. Dupont, and J. Strominger. 1985. Two genes encoding steroid 21 hydroxylase are located near the genes encoding the fourth component of complement in man. Proc. Natl. Acad. Sci. 82: 1089-1093.

3. White, P.C., M.I. New, and B. Dupont. 1986. Structure of human steroid 21-hydroxylase genes. Proc. Natl. Acad. Sci. 83: 5111-5115.

4. Higashi, Y., A. Tanae, H. Inoue, T. Hiromasa, and Y. Fujii-Kuriyama. 1988. Aberrant splicing and missense mutations causes steroid 21-hydroxylase $[\mathrm{P}-450$ (C21)] deficiency in 
humans: Possible gene conversion products. Proc. Natl. Acad. Sci. 85: 7486-7490.

5. Rodrigues, N.R., I. Dunham, C.U. Yu, M.C. Carroll, R.R. Porter, and R.D. Campbell. 1987. Molecular characterization of the HLA-linked steroid 21hydroxylase B gene from an individual with congenital adrenal hyperplasia. EMBO J. 6: 1653-1661.

6. Collier, S., P.J. Sinnott, P.A. Dyer, D.A. Price, R. Harris, and T. Strachan. 1989. Pulsed field gel electrophoresis identifies a high degree of variability in the number of tandem 21. hydroxylase and complement $\mathrm{C} 4$ gene repeats in 21-hydroxylase deficiency haplotypes. $E M B O \quad J$. 8: 1393-1402.

7. Sinnott, P.J., C. Livieri, M. Sampietro, M. Marconi, R. Harris, F. Severi, and T. Strachan. 1992. CYP21/C4 gene organization in Italian 21-hydroxylase deficiency families. Hum. Genet. (in press).

8. Sinnott, P., S. Collier, C. Costigan, P.A. Dyer, R. Harris, and T. Strachan. 1990. Genesis by meiotic unequal crossover of a de novo deletion that contributes to steroid 21-hydroxylase deficiency. Proc. Natl. Acad. Sci. 87: 2107-2111.

9. Strachan, T. 1990. Molecular pathology of congenital adrenal hyperplasia. Clin. Endocrinol. 32: 373-393.

10. Strachan, T. and P.C. White. 1991. Molecular pathology of steroid 21hydroxylase deficiency. I. Steroid Biochem. Mol. Biol. 40: 537-543.

11. Wood, W.I., J. Gitschier, L.A. Lasky, and R.M. Lawn. 1985. Base composition-independent hybridization in tetramethyl ammonium chloride: A method for oligonucleotide screening of highly complex gene libraries. Proc. Natl. Acad. Sci. 82: 1585-1588.

12. Guo, L.-H. and R. Wu. 1983. Exonuclease III: Use for DNA sequencing and in specific deletions of nucleotides. Methods Enzymol. 100: 60-96.

13. New, M.I., P.C. White, S. Pang, B. Dupont, and P.W. Speiser. 1989. The adrenal hyperplasias. In The metabolic basis of inherited disease (ed. C.R. Scriver, A.L. Beaudet, and D. Valle), pp. 1881-1918. McGraw-Hill, New York.

14. Amor, M., K.L. Parker, H. Globerman, M.I. New, and P.C. White. 1988.
Mutation in the CYP21B gene (Ile$172 \rightarrow$ Asn) causes steroid 21-hydroxylase deficiency. Proc. Natl. Acad. Sci. 85: $1600-1604$.

15. Chiou, S.-H., M.-C. Hu, and B.-C. Chung. 1990. A missense mutation at $\mathrm{Ile}^{172} \rightarrow$ Asn or $\mathrm{Arg}^{356} \rightarrow$ Trp causes steroid 21-hydroxylase deficiency. $J$. Biol. Chem. 265: 3549-3552.

16. Tusie-Luna, M.T., P. Traktman, and P.C. White. 1990. Determination of functional effects of mutations in the steroid 21-hydroxylase gene (CYP21) using recombinant vaccinia virus. $J$. Biol. Chem. 265: 20916-20922.

17. Globerman, H., M. Amor, K.L. Parker, M.I. New, and P.C. White. 1988. Nonsense mutation causing steroid 21-hydroxylase deficiency. J. Clin. Invest. 82: 139-144.

18. Higashi, Y., H. Yoshioka, M. Yamane, O. Gotoh, and Y. Fujii-Kuriyama. 1986. Complete nucleotide sequence of two steroid 21-hydroxylase genes tandemly arranged in human chromosome: A pseudogene and a genuine gene. Proc. Natl. Acad. Sci. 83: 2841-2845.

19. Owerbach, D., Y.M. Crawford, and M.B. Draznin. 1990. Direct analysis of CYP21B genes in 21-hydroxylase deficiency using polymerase chain reaction amplification. Mol. Endocrinol. 4: 125-131.

20. Mornet, E., P. Crete, F. Kuttenn, M.C. Raux-Demay, J. Boue, P.C. White, and A. Boue. 1991. Distribution of deletions and seven point mutations on CYP21B genes in three clinical forms of steroid 21-hydroxylase deficiency. Am. J. Hum. Genet. 48: 79-88.

21. Newton, C.R., A. Graham, L.E. Heptinstall, S.J. Powell, C. Summers, N. Kalsheker, J.C. Smith, and A.F. Markham. 1989. Analysis of any point mutation in DNA. The amplification refractory mutation system (ARMS). Nucleic Acid Res. 17: 2503-2516.

Received September 3, 1991; accepted in revised form Novernber 19, 1991. 




\section{A method for specific amplification and PCR sequencing of individual members of multigene families: application to the study of steroid 21-hydroxylase deficiency.}

S Collier, M Tassabehji and T Strachan

Genome Res. 1992 1: 181-186

Access the most recent version at doi:10.1101/gr.1.3.181

References This article cites 19 articles, 10 of which can be accessed free at:

http://genome.cshlp.org/content/1/3/181.full.html\#ref-list-1

License

Email Alerting

Receive free email alerts when new articles cite this article - sign up in the box at the Service top right corner of the article or click here.

\section{Affordable, Accurate Sequencing.}

To subscribe to Genome Research go to:

https://genome.cshlp.org/subscriptions 